Computer Optics and Nanophotonics

\title{
FOR THE ANNIVERSARY OF PROFESSOR S.N. KHONINA
}

\author{
E.I. Kolomiets
}

Samara National Research University, Samara, Russia

\begin{abstract}
The article briefly describes the scientific and pedagogical achievements of Doctor of Physical and Mathematical Sciences, Prof. Svetlana N. Khonina.

Keywords: Professor, Doctor of Physical and Mathematical Sciences, diffractive optics, singular optics, sharp focus, polarization conversion

Citation: Kolomiets EI. For the anniversary of professor S.N. Khonina. CEUR Workshop Proceedings, 2016; 1638: 207-216. DOI: 10.18287/1613-0073-20161638-207-216
\end{abstract}

\section{Introduction}

Recently Doctor of Physical and Mathematical Sciences, chief researcher of the Image Processing Systems Institute of the RAS and part-time professor of Technical Cybernetics Department of Samara National Research University Svetlana Nickolayevna Khonina celebrated her anniversary. The article briefly describes scientific and pedagogical achievements of S.N. Khonina.

\section{IPSI RAS}

In 1989 S.N. Khonina graduated with honors from the Kuibyshev Aviation Institute on specialty "Applied Mathematics" at the systems engineering faculty. After graduation she started working as an engineer-programmer at the Samara branch of the Central Design Bureau for Unique Instrumentation of the USSR Academy of Sciences, which was transformed in 1993 into the Image Processing Systems Institute of the Russian Academy of Sciences (IPSI RAS). Since 1993 S.N. Khonina was a researcher, since 1994 - a senior researcher, and since 2002 - a leading researcher of the IPSI RAS. In 2015 she took the position of chief researcher of the laboratory of laser measurements of IPSI RAS.

Her scientific career went as follows: in 1995 she defended her candidate thesis on "Optical methods of calculation of uncorrelated features and image structuring", and in 2001 - a doctoral thesis on "Formation of self-reproducing laser beams by means of diffractive optical elements, matched with the mode composition", by specialty 
01.04.05 "Optics" in the Samara State Aerospace University (SSAU). The results of the thesis research were reflected in the chapters of several monographs edited by Corresponding Member of the Russian Academy of Sciences V.A. Soifer [1-3].

Currently S.N. Khonina has a list of 450 scientific works, including 9 monographs and 4 patents: in the Russian Science Index database - 417 publications and 3407 references (Hirsch index is 27), in the international database Scopus - 235 publications and 1727 references (Hirsch index is 21), in the international database Web of Science - 118 publications and 827 references (Hirsch index is 17).

\section{Samara University}

S.N. Khonina combines scientific activity with teaching. Since September, 1995 she has been working part-time at the Department of Technical Cybernetics of SSAU. Starting with the position of assistant and then taking successively positions of a docent and a professor, in 2007 she received the title of professor in Technical Cybernetics Department.

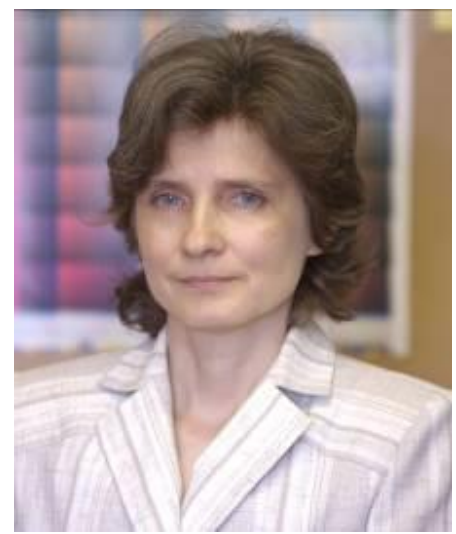

Fig. 1. Doctor of Physical and Mathematical Sciences, Professor S.N. Khonina

S.N. Khonina reads lecture courses «Optical computer science» and «Design of the elements of optical systems», conducts practical and laboratory classes for students in directions "Applied Mathematics and Physics", "Applied Mathematics and Informatics", leads the research work of bachelors, masters, and postgraduate students, she has prepared four candidates of physical and mathematical sciences, and she is a member of two dissertational councils. During her educational activity she has prepared more than two dozen manuals, and she is a co-author of several monographs [1-3]. S. N. Khonina is the executive performer of network master program "Mathematical methods of modeling and functional design of information systems and optical instruments" which is implemented in cooperation with the St. Petersburg University of Information Technologies, Mechanics and Optics in the frame of the Program of improving the competitiveness of SSAU among the world's leading research and education centers. Since 2014 she has been holding the position of head of the SSAU basic department in IPSI RAS “Optoinformational technologies”. 


\section{The main scientific results}

S.N. Khonina obtained first scientific results under supervising of Prof. V.A. Soifer and under guidance of Prof. V.V. Kotlyar and Prof. M.A. Golub [4-9]. Research on fingerprint recognition [10-12] based on the directions field method formed the basis of her candidate`s thesis. Directions field method allows to extract and convert the information contained in images with structural redundancy (which include fingerprints, interferograms, and other "striped" images) to a more convenient and compact form [13-16]. After such a processing, which may be performed optically, further identification of structurally redundant images is simplified substantially.

The main result of the doctoral thesis of S. Khonina is development of adaptive iterative techniques for calculating the phase diffractive optical elements (DOE) designed to focus the coherent radiation in the plane (or a set of planes and a 3D area) at a predetermined distance with a certain intensity distribution [17-21], as well as to form multimode laser beams with the properties of self- reproduction in different diffraction orders [22-24]. The methods are based on the decomposition of the defined distributions into particular solutions of the Helmholtz equation, such as plane and spherical waves, Gaussian, Bessel, spheroidal and hypergeometric modes, Airy beams, optical vortices [25-32]. Iterative and combined digital holography techniques have been used for phase encoding of DOEs, which were fabricated by electron lithography methods. Experimental testing has confirmed the accuracy of the theoretical results [33-42].

The methods developed for diffraction formation of laser beams with special properties (rotation, periodic reproduction, 3D localization) allowed to extend the functional possibilities of the optical traps [43-47] used for nondestructive capture and manipulation with microparticles.

The multi-channel DOEs matched with different orthogonal basis were applied for solving problems related to measurement of the orbital angular momentum of rotating multimode laser beams [37, 40, 48, 49], mode division multiplexing and selections in optical fibers [50-53], as well as restoring the wavefront using Zernike basis functions [54-57].

One of the problems that S.N. Khonina currently investigates is the diffraction limit overcoming in focusing systems with high numerical aperture. To solve this problem several methods have been developed to optimize the complex transmission function of sharp-focusing system at different polarizations of laser radiation [58-67]. Supplement of the optical focusing system with DOEs allows control the 3D distribution of the intensity in the focal region, to redistribute the components of the electromagnetic field, and to reduce the size of the focal spot.

A remarkable fact was discovered in the course of studies on sharp focusing. It was the possibility to overcome the diffraction limit in the near field zone using the axicons with subwavelength period [68-73]. The generation of the longitudinal component of electromagnetic field on the optical axis in the focal region while entering into the beam with linear and circular polarization of the vortex phase in conditions of sharp focusing was theoretically shown. For the first time the excitation in this case of a strong longitudinal component of the electromagnetic field was theoretically predicted and experimentally confirmed. 
To implement best focus conditions it is necessary not only to increase the numerical aperture of the focusing system [71, 74-76], but also to provide a definite combination of polarization and spatial properties of the focused beams. Most existing lasers emit a linearly polarized light, but the most interesting results were found when radiation with radial and azimuthal polarization is focused. Therefore a significant part of S.N. Khonina research is devoted to polarization conversion. Theoretical research was carried out on polarization transformation by using the phase singularities in laser beams (vortex or linear), and also due to the anisotropy of the optical medium in nonparaxial conditions. The efficiency of the DOE for polarization transformation was confirmed experimentally [77-85].

Studies on sharp focusing often led to a comparison of properties of the lens and the axicon. In 2009 S.N. Khonina proposed and theoretically investigated a new diffractive optical element - fracxicon [86], whose phase function is described by a fractional power-law dependence on the radius. Thus, a parabolic lens or an axicon are just special cases of the fracxicon. Variations of the power dependence allow to receive combined properties of several optical elements in one element, that provides control of both longitudinal and transverse distribution of the intensity in the focal region [8790].

Another object in the field of scientific interests of S.N. Khonina is the study of chromatic properties of DOEs [91-93], which is important both in imaging systems [94-98] and in the laser processing of materials [99-102]. She has considered the influence of the light wavelength deviation from the base one in the manufacture of DOE, as well as the effect of broadening the spectrum while using nonmonochromatic radiation sources. I should also note the following areas of her scientific interests [103-108] related with research in the field of diffractive nanophotonics and photovoltaics.

\section{Conclusion}

In conclusion, we would like to wish Svetlana Nikolaevna Khonina to get excellent students to continue and expand of scientific research!

\section{References}

1. Methods for Computer Design of Diffractive Optical Elements / V.A. Soifer, V.V. Kotlyar, N.L. Kazanskiy, L.L. Doskolovich, S.I. Kharitonov, S.N. Khonina, V.S. Pavelyev, R.V. Skidanov, A.V. Volkov, D.L. Golovashkin, V.S. Solovyev, G.V. Usplenyev; ed. V. A. Soifer - John Wiley \& Sons, Inc., New York, 2002, 765 p.

2. Computer Design of Diffractive Optics / D.L. Golovashkin, V.V. Kotlyar, V.A. Soifer, L.L. Doskolovich, N.L. Kazanskiy, V.S. Pavelyev, S.N. Khonina, R.V. Skidanov; ed. V.A. Soifer - Cambridge Inter. Scien. Pub. Ltd.\& Woodhead Pub. Ltd., 2012, 896 p.

3. Diffractive Nanophotonics / A.V. Gavrilov, D.L. Golovashkin, L.L. Doskolovich, P.N. Dyachenko, S.N. Khonina, V.V. Kotlyar, A.A. Kovalev, A.G. Nalimov, D.V. Nesterenko, V.S. Pavelyev, Y.O. Shuyupova, R.V. Skidanov, V.A. Soifer; ed. by V.A. Soifer, CRC Press, Taylor \& Francis Group, CISP, Boca Raton, 2014, 679 p.

4. Khonina SN, Kotlyar VV, Soifer VA. Fast Hankel transform for focusator synthesis. Optik, 1991; 88(4): 182-184. 
5. Kotlyar VV, Soifer VA, and Khonina SN. Phase optical components for the generation of free-space quasimodes. Soviet Journal of Quantum Electronics, 1991; 21(11): 1278-1281.

6. Khonina SN, Kotlyar VV, Shinkaryev MV, Soifer VA, Uspleniev GV. The phase rotor filter. Journal of Modern Optics, 1992; 39(5): 1147-1154.

7. Doskolovich LL, Khonina SN, Kotlyar VV, Nikolsky IV, Soifer VA, Uspleniev GV. Focusators into a ring. Optical and Quantum Electronics, 1993; 25(11): 801-814.

8. Soifer VA, Golub MA, Khonina SN. Decorrelated features of images extracted with the aid of optical Karhunen-Loeve expansion. Pattern Recognition and Image Analysis, 1993; 3(3): 289-295.

9. Soifer VA, Khonina SN. Stability of the Karhunen-Loeve expansion in the problem of pattern recognition. Pattern Recognition and Image Analysis, 1994; 4(2): 137-148.

10. Soifer VA, Kotlyar VV, Khonina SN, Skidanov RV. Optical-digital methods of fingerprint identification. Optics and Lasers in Engineering, 1998; 29(4-5): 351-359.

11. Kotlyar VV, Soifer VA, Khonina SN, Skidanov RV. Fingerprint recognition using Hadamard-expanded partial images. Proceedings of SPIE, 1997; 3238: 66-73.

12. Khonina SN, Kotlyar VV, Skidanov RV, and Soifer VA. Optodigital system for identifying fingerprints in real time. Journal of Optical Technology, 2003; 70(8): 586-589.

13. Khonina SN, Kotlyar VV, Soifer VA, Dvoryanova TP. Optical-digital method for detecting distortions of microcrystal structure on a tear crystallogram. Proceedings of SPIE, 1995; 2363: 249-255.

14. Soifer VA, Khonina SN. Optical structuring for analysis of contour images. Pattern Recognition and Image Analysis, 1996; 6(1): 71-72.

15. Soifer VA, Kotlyar VV, Khonina SN, Khramov AG. The method of the direction field in the interpretation and recognition of images with structure redundancy. Pattern Recognition and Image Analysis, 1996; 6(4): 710-724.

16. Soifer VA, Kotlyar VV, Khonina SN, Khramov AG, Skidanov RV. Image recognition using a directional field technique. Proceedings of SPIE, 1998; 3346: 238-258.

17. Khonina SN, Kotlyar VV, Soifer VA. Calculation of the focusators into a longitudinal line segment and study of a focal area. Journal of Modern Optics, 1993; 40(5): 761-769.

18. Kotlyar VV, Khonina SN, Soifer VA. Iterative calculation of diffractive optical elements focusing into a three dimensional domain and the surface of the body of rotation. Journal of Modern Optics, 1996; 43(7): 1509-1524.

19. Kotlyar VV, Khonina SN, Soifer VA. Calculation of phase formers of non-diffracting images and a set of concentric rings. Optik 1996; 102(2): 45-50.

20. Volkov AV, Kotlyar VV, Moiseev OV, Rybakov OE, Skidanov RV, Soifer VA, Khonina SN. Binary diffraction optical element focusing a Gaussian beam to a longitudinal segment. Optics and Spectroscopy, 2000; 89(2): 318-323.

21. Khonina SN, Kotlyar VV, Skidanov RV, Soifer VA. Levelling the focal spot intensity of the focused Gaussian beam. Journal of Modern Optics, 2000; 47(5): 883-904.

22. Kotlyar VV, Soifer VA, Khonina SN. Rotation of Gauss-Laguerre multimodal light beams in free space, Technical Physics Letters 1997; 23(9): 657-658.

23. Khonina SN, Kotlyar VV, Soifer VA, Lautanen J, Honkanen M, Turunen J. Generating a couple of rotating nondiffracting beams using a binary-phase DOE. Optik, 1999; 110(3): 137-144.

24. Khonina SN, Kotlyar VV, and Soifer VA. Self-reproduction of multimode HermiteGaussian beams. Technical Physics Letters, 1999; 25(6): 489-491.

25. Khonina SN, Kotlyar VV, Soifer VA, Honkanen M, Lautanen J, Turunen J. Generation of rotating Gauss-Laguerre modes with binary-phase diffractive optics. Journal of Modern Optics, 1999; 46(2): 227-238.

26. Khonina SN, Volotovskij SG, Sojfer VA. A method to compute eigenvalues of prolate spheroidal functions of zero order. Doklady Akademii Nauk, 2001; 376(1): 30-33. 
27. Khonina SN, Kotlyar VV, Soifer VA, Jefimovs K, Paakkonen P, Turunen J. Astigmatic Bessel laser beams. Journal of Modern Optics, 2004; 51(5): 677-686.

28. Kotlyar VV, Kovalev AA, Skidanov RV, Khonina SN, and Turunen J. Generating hypergeometric laser beams with a diffractive optical element. Applied Optics, 2008; 47(32): 6124- 6133

29. Khonina SN, Volotovsky SG. Bounded one-dimensional Airy beams: laser fan. Computer Optics, 2008; 32(2): 168-174.

30. Khonina SN, Balalaev SA. Hypergeometrical beams in a near zone of diffraction within the limits of scalar model. Computer Optics, 2009; 33(4): 427-435.

31. Khonina SN. Specular and vortical Airy beams. Optics Communications, 2011; 284: 42634271.

32. Kirilenko MS, Khonina SN. Coding of an optical signal by a superposition of spheroidal functions for undistorted transmission of information in the lens system. Proceedings of SPIE, 2014; 9156: 91560J-9 pp.

33. Khonina SN, Kotlyar VV. Bessel-mode formers. Proceedings of SPIE 1994; 2363: 184190.

34. Kotlyar VV, Khonina SN, Soifer VA. Algorithm for the generation of non-diffracting Bessel modes. Journal of Modern Optics, 1995; 42(6): 1231-1239.

35. Kotlyar VV, Khonina SN, Soifer VA. Generalized Hermite beams in free space. Optik, 1998; 108(1): 20-26.

36. Kotlyar VV, Khonina SN, Soifer VA. Light field decomposition in angular harmonics by means of diffractive optics. Journal of Modern Optics, 1998; 45(7): 1495-1506.

37. Khonina SN, Kotlyar VV, Soifer VA. Diffraction optical elements matched to the GaussLaguerre modes. Optics and Spectroscopy, 1998; 85(4): 636-644.

38. Khonina SN, Kotlyar VV, Soifer VA, Paakkonen P, Simonen J, Turunen J. An analysis of the angular momentum of a light field in terms of angular harmonics. Journal of Modern Optics, 2001; 48(10): 1543-1557.

39. Khonina SN, Kotlyar VV, Soifer VA, Jefimovs K, Turunen J. Generation and selection of laser beams represented by a superposition of two angular harmonics. Journal of Modern Optics, 2004; 51(5): 761-773.

40. Almazov AA, Khonina SN, Kotlyar VV. Using phase diffraction optical elements to shape and select laser beams consisting of a superposition of an arbitrary number of angular harmonics, Journal of Optical Technology, 2005; 72(5): 391-399.

41. Khonina SN, Balalayev SA, Skidanov RV, Kotlyar VV, Paivanranta B, Turunen J. Encoded binary diffractive element to form hyper-geometric laser beams. Journal of Optics A: Pure and Applied Optics, 2009; 11: 065702-7 pp.

42. Khonina SN, Balalaev SA. The comparative analysis of the intensity distributions formed by diffractive axicon and diffractive logarithmic axicon. Computer Optics, 2009; 33(2): $162-174$.

43. Soifer VA, Kotlyar VV, Khonina SN. Optical microparticle manipulation: advances and new possibilities created by diffractive optics. Physics of Particles and Nuclei, 2004; 35(6): 733-766

44. Khonina SN, Skidanov RV, Kotlyar VV, Soifer VA, Turunen J. DOE-generated laser beams with given orbital angular moment: application for micromanipulation. Proceedings of SPIE, 2005; 5962: 59622W-12 pp.

45. Kotlyar VV, Khonina SN, Skidanov RV, and Soifer VA. Rotation of laser beams with zero of the orbital angular momentum. Optics Communications, 2007; 274: 8-14.

46. Khonina SN, Skidanov RV, Moiseev OY. Airy laser beams generation by binary-coded diffractive optical elements for microparticles manipulation. Computer Optics, 2009; 33(2): 138-146. 
47. Skidanov RV, Khonina SN, Morozov AA. Optical rotation of microparticles in hypergeometric beams formed by diffraction optical elements with multilevel microrelief. Journal of Optical Technology, 2013; 80(10): 585-589.

48. Khonina SN, Kotlyar VV, Soifer VA, Paakkonen P, Turunen J. Measuring the light field orbital angular momentum using DOE. Optical Memory and Neural Networks, 2001; 10(4): 241-255.

49. Khonina SN, Almazov AA. Design of multi-channel phase spatial filter for selection of Gauss-Laguerre laser modes. Proceedings of SPIE, 2002; 4705: 30-39.

50. Karpeev SV, Pavelyev VS, Khonina SN, Kazanskiy NL, Gavrilov AV, Eropolov VA. Fibre sensors based on transverse mode selection. Journal of Modern Optics, 2007; 54(6): 833-844. DOI: 10.1080/09500340601066125.

51. Khonina SN, Striletz AS, Kovalev AA, Kotlyar VV. Propagation of laser vortex beams in a parabolic optical fiber. Proceedings of SPIE, 2010; 7523: 75230B-12 p.

52. Khonina SN, Kazanskiy NL, Soifer VA. Optical vortices in a fiber: mode division multiplexing and multimode self-imaging. Chapter 15 in "Recent progress in optical fiber research", ed. by M.Yasin, S.W. Harun, H. Arof, INTECH publisher, Croatia, 2012, 26 p.

53. Lyubopytov VS, Tlyavlin AZ, Sultanov AK, Bagmanov VK, Khonina SN, Karpeev SV, Kazanskiy NL. Mathematical model of completely optical system for detection of mode propagation parameters in an optical fiber with few-mode operation for adaptive compensation of mode coupling. Computer Optics, 2013; 37(3): 352-359.

54. Ha Y, Zhao D, Wang Y, Kotlyar VV, Khonina SN, Soifer VA. Diffractive optical element for Zernike decomposition. Proceedings of SPIE, 1998; 3557: 191-197.

55. Khonina SN, Kotlyar VV, Wang Ya. Diffractive optical element matched with Zernike basis. Pattern Recognition and Image Analysis, 2001; 11(2): 442-445.

56. Khonina SN, Kotlyar VV, Kirsh DV. Zernike phase spatial filter for measuring the aberrations of the optical structures of the eye. Journal of Biomedical Photonics Engineering, 2015; 1(2): 146-153.

57. Porfirev AP, Khonina SN. Experimental investigation of multi-order diffractive optical elements matched with two types of Zernike functions. Proceedings of SPIE, 2016; 9807: 98070E-9pp.

58. Khonina SN, Volotovsky SG. Investigation of axicon application in high-aperture focusing system. Computer Optics, 2010; 34(1): 35-51.

59. Khonina SN, Ustinov AV, Volotovsky SG, Kovalev AA. Calculation of diffraction of the linearly-polarized limited beam with uniform intensity on high-aperture binary micro-axicons in a near zone. Computer Optics, 2010; 34(4): 443-460.

60. Khonina SN, Kazanskiy NL, Volotovsky SG. Influence of vortex transmission phase function on intensity distribution in the focal area of high-aperture focusing system. Optical Memory and Neural Networks (Information Optics), 2011; 20(1): 23-42. DOI: 10.3103/S1060992X11010024.

61. Khonina SN, Ustinov AV, Pelevina EA. Analysis of wave aberration influence on reducing focal spot size in a high-aperture focusing system. Journal of Optics, 2011; 13: 095702-13pp.

62. Khonina SN, Alferov SV, Karpeev SV. Strengthening the longitudinal component of the sharply focused electric field by means of higher-order laser beams. Optics Letters, 2013; 38(17): 3223-3226.

63. Khonina SN and Golub I. How low can STED go? Comparison of different write-erase beam combinations for stimulated emission depletion microscopy. Journal of Optical Society of America A, 2012; 29(10): 2242-2246.

64. Khonina SN, Kazanskiy NL, Ustinov AV, Volotovskiy SG. The lensacon: nonparaxial effects. Journal of Optical Technology, 2011; 78(11): 724-729. DOI: 10.1364/JOT.78.000724.

65. Khonina SN and Golub I. Optimization of focusing of linearly polarized light. Optics Letters, 2011;36(3): 352-354. 
66. Khonina SN, Ustinov AV. Reducing of the focal spot size at radial polarization by means of the binary annular element. Computer Optics, 2012; 36(2): 219-226.

67. Khonina SN, Ustinov AV. Analysis of interference of cylindrical laser beams generated by ring optical elements with a vortex phase at sharp focusing. Computer Optics, 2015; 39(1): 12-25. DOI: 10.18287/0134-2452-2015-39-1-12-25.

68. Khonina SN. Formation of an axial line with the reduced cross-section size for linear polarization of an illuminating beam by means of high-aperture binary axicons without axial symmetry. Computer Optics, 2010; 34 (4): 461-468.

69. Khonina SN, Nesterenko DV, Morozov AA, Skidanov RV, Soifer VA. Narrowing of a light spot at diffraction of linearly-polarized beam on binary asymmetric axicons. Optical Memory and Neural Networks (Information Optics), 2012; 21(1): 17-26.

70. Khonina SN, Serafimovich PG, Savelyev DA, Pustovoi IA. Diffraction at binary microaxicons in the near field. Journal of Optical Technology, 2012; 79(10): 626-631.

71. Khonina SN and Savelyev DA. High-aperture binary axicons for the formation of the longitudinal electric field component on the optical axis for linear and circular polarizations of the illuminating beam. Journal of Experimental and Theoretical Physics, 2013; 117(4): 623-630.

72. Khonina SN, Karpeev SV, Alferov SV, Savelyev DA, Laukkanen J, Turunen J. Experimental demonstration of the generation of the longitudinal E-field component on the optical axis with high-numerical-aperture binary axicons illuminated by linearly and circularly polarized beams. Journal of Optics, 2013; 15: 085704-9 pp.

73. Ustinov AV, Khonina SN. Analysis of laser beam diffraction by axicon with the numerical aperture above limiting. Computer Optics, 2014; 38(2): 213-222.

74. Khonina SN, Ustinov AV, Volotovsky SG. Shaping of spherical light intensity based on the interference of tightly focused beams with different polarizations. Optics \& Laser Technology, 2014; 60: 99-106.

75. Khonina SN, Golub I. Enlightening darkness to diffraction limit and beyond: comparison and optimization of different polarizations for dark spot generation. Journal of Optical Society of America A, 2012; 29(7): 1470-1474.

76. Degtyarev SA, Ustinov AV, Khonina SN. Nanofocusing by sharp edges. Computer Optics, 2014; 38(4): 629-637.

77. Khonina SN, Karpeev SV. Grating-based optical scheme for the universal generation of inhomogeneously polarized laser beams. Applied Optics, 2010; 49(10): 1734-1738.

78. Khonina SN, Karpeev SV. Generating inhomogeneously polarized higher-order laser beams by use of diffractive optical elements. Journal of Optical Society of America A, 2011; 28(10): 2115-2123.

79. Khonina SN, Karpeev SV, Alferov SV. Polarization converter for higher-order laser beams using a single binary diffractive optical element as beam splitter. Optics Letters, 2012; 37(12): 2385-2387.

80. Alferov SV, Karpeev SV, Khonina SN, Moiseev OYu. Experimental study of focusing of inhomogeneously polarized beams generated using sector polarizing plates. Computer Optics, 2014; 38(1): 57-64.

81. Alferov SV, Khonina SN, and Karpeev SV. Study of polarization properties of fiber-optics probes with use of a binary phase plate. Journal of Optical Society of America A, 2014; 31(4): 802-807.

82. Khonina SN, Karpeev SV, Alferov SV. Theoretical and an experimental research of polarizing transformations in uniaxial crystals for generation cylindrical vector beams of high orders. Computer Optics, 2014; 38(2): 171-180.

83. Khonina SN, Paranin VD, Karpeev SV, Morozov AA. Study of polarization transformations and interaction of ordinary and extraordinary beams in nonparaxial regime. Computer Optics, 2014; 38(4): 598-605. 
84. Khonina SN, Morozov AA, Karpeev SV. Effective transformation of a zero-order Bessel beam into a second-order vortex beam using a uniaxial crystal. Laser Physics, 2014; 24 : 056101-5 pp.

85. Khonina SN, Karpeev SV, Alferov SV, Soifer VA. Generation of cylindrical vector beams of high orders using uniaxial crystals. Journal of Optics, 2015; 17: 065001-11 pp.

86. Khonina SN, Volotovsky SG. Fracxicon - diffractive optical element with conical focal domain. Computer Optics, 2009; 33(4): 401-411.

87. Ustinov AV, Khonina SN. Generalized lens: Calculation of distribution on the optical axis. Computer Optics, 2013; 37(3): 307-315.

88. Khonina SN, Ustinov AV. Diffraction of a Gaussian beam on the generalized lens. Computer Optics, 2013; 37(4): 443- 450.

89. Ustinov AV, Khonina SN. Analysis of flat beam diffraction by divergent fracxicon in nonparaxial mode. Computer Optics, 2014; 38(1): 42-50.

90. Ustinov AV, Khonina SN. Fracxicon as hybrid element between the parabolic lens and the linear axicon. Computer Optics, 2014; 38(3): 402-411.

91. Doskolovich LL, Kazanskiy NL, Khonina SN, Skidanov RV, Heikkilä N, Siitonen S, Turunen J. Design and investigation of color separation diffraction gratings. Applied Optics, 2007; 46(15): 2825-2830. DOI: 10.1364/AO.46.002825.

92. Kazanskiy NL, Khonina SN, Skidanov RV, Morozov AA, Kharitonov SI, Volotovskiy SG. Formation of images using multilevel diffractive lens. Computer Optics, 2014; 38(3): 425434.

93. Khonina SN, Ustinov AV, Skidanov RV, Morozov AA. Comparative study of the spectral characteristics of aspheric lenses. Computer Optics, 2015; 39(3): 363-369. DOI: 10.18287/0134-2452-2015-39-3-363-369.

94. Kazanskiy NL, Kharitonov SI, Karsakov AV, Khonina SN. Modeling action of a hyperspectrometer based on the Offner scheme within geometric optics. Computer Optics, 2014; 38(2): 271-280.

95. Kazanskiy NL, Kharitonov SI, Khonina SN, Volotovskiy SG, Strelkov YuS. Simulation of hyperspectrometer on spectral linear variable filters. Computer Optics, 2014; 38(2): 256-270.

96. Kazanskiy NL, Kharitonov SI, Khonina SN. Simulation of a hyperspectrometer based on linear spectral filters using vector Bessel beams. Computer Optics, 2014; 38(4): 770-776.

97. Kazanskiy NL, Kharitonov SI, Khonina SN, Volotovskiy SG. Simulation of spectral filters used in hyperspectrometer by decomposition on vector Bessel modes. Proceedings of SPIE, 2015; 9533: 95330L-7 pp. DOI: 10.1117/12.2183429.

98. Karpeev SV, Khonina SN, Kharitonov SI. Study of the diffraction grating on the convex surface as a dispersive element. Computer Optics, 2015; 39(2): 211-217. DOI: 10.18287/01342452-2015-39-2-211-217.

99. Alferov SV, Karpeev SV, Khonina SN, Tukmakov KN, Moiseev OYu, Shulyapov SA, Ivanov KA, Savel'ev-Trofimov AB. On the possibility of controlling laser ablation by tightly focused femtosecond radiation. Quantum Electronics, 2014; 44(11): 1061-1065.

100. Karpeev SV, Alferov SV, Khonina SN, Kudryashov SI. Study of the broadband radiation intensity distribution formed by diffractive optical elements. Computer Optics, 2014; 38(4): 689-694.

101. Zayarny DA, Ionin AA, Kudryashov SI, Makarov SV, Rudenko AA, Bezhanov SG, Uryupin SA, Kanavin AP, Emel'yanov VI, Alferov SV, Khonina SN, Karpeev SV, Kuchmizhak AA, Vitrik OB, and Kulchin YuN. Nanoscale boiling during single-shot femtosecond laser ablation of thin gold films. JETP Letters, 2015; 101(6): 394-397.

102. Khonina SN, Degtyarev SA, Porfirev AP, Moiseev OYu, Poletaev SD, Larkin AS, SavelyevTrofimov AB. Study of focusing into closely spaced spots at illuminating diffractive optical element by short pulse laser beam. Computer Optics, 2015; 39(2): 187-196. DOI: 10.18287/0134-2452-2015-39-2-187-196. 
103. Kazanskiy NL, Serafimovich PG, Khonina SN. Harnessing the Guided-Mode Resonance to Design Nanooptical Transmission Spectral Filters. Optical Memory and Neural Networks (Information Optics), 2010; 19(4): 318-324. DOI: 10.3103/S1060992X10040090.

104. Kharitonov SI, Volotovsky SG, Khonina SN, Kazanskiy NL. Differential calculation method of diffraction of x-rays by crystal: scalar theory. Computer Optics, 2015; 39(4): 469-479. DOI: 10.18287/0134-2452-2015-39-4-469-479.

105. Kazanskiy NL, Serafimovich PG, Khonina SN. Use of photonic crystal cavities for temporal differentiation of optical signals. Optics Letters, 2013; 38(7): 1149-1151. DOI: 10.1364/OL.38.001149.

106. Khonina SN, Savelyev DA, Kazanskiy NL. Vortex phase elements as detectors of polarization state. Optics Express, 2015; 23(14): 17845-17859. DOI: 10.1364/OE.23.017845.

107. Khonina SN, Savelyev DA, Kazanskiy NL. Analysis of polarization states at sharp focusing. Optik - International Journal for Light and Electron Optics, 2016; 127(6): 3372-3378. DOI: 10.1016/j.ijleo.2015.12.108.

108. Juneja S, Sudhakar S, Khonina SN, Skidanov RV, Porfirev AP, Moissev OY, Kazanskiy NL, Kumar S. Nanocrystalline silicon thin films and grating structures for solar cells. Proceedings of SPIE, 2016; 9807: 98070F-8 pp. 